\title{
Entrants to the labour force: changes in market conditions and educational qualifications of youth
}

\author{
G Brian Thompson*
}

This study examines the position of youth in the New Zealand labour market over the past 2 decades, including links between education and the labour market. Changes in the labour market position of school leavers, teenagers, and older youth are described. Changes in the supply and value of school qualifications of entrants to the labour force are examined and a data series on school qualifications of entrants to clerical jobs shows the influence of fluctuations in slackness of the labour market. The results indicate, for entry to these jobs, a selection function of school qualifications which entails declining exchange value as the supply of qualifications increases, in contrast to constant exchange value within the education system.

\section{Introduction}

The position of youth in the New Zealand labour market is of current interest to commentators on both labour economics and education. In view of evidence that recent unemployment in New Zealand has been largely youth unemployment (Hicks and Brosnan, 1982), an analysis of the labour market would be incomplete without consideration of the youth component. The increases in unemployment associated with the recession since 1975 have resulted in such sluggishness in the exit from school and entry to employment that "school-to-work programmes" for youth have become a feature of New Zealand secondary schools. Hence the position of youth in the labour market has become of more concern to educators than in earlier decades. The analysis given here is of past changes in the labour market position of young people, particularly the market position of firsttime entrants to the labour force and their stock of educational qualifications.

The market conditions of youth

Unemployment levels reported in the 5-yearly census over the last 3 decades are given in Table 1, as a ratio of unemployed to full-time labour force in the age group. Following 1966 there have been accelerated increases in teenage (15-19 years) unemployment but only after 1976 has there been a significant change for prime-age workers and young adults. The increases have been much larger for teenagers than any increases in older age groups. In this period increases in teenage unemployment have been a phenomenon not only of the recession since 1975; smaller increases occurred earlier, between 1966 and 1971 , probably as an early response to the short-term slow down in economic activity in

* Senior lecturer in the Department of Education, Victoria University of Wellington. The author wishes to thank Amanda Craddock for assistance with data analysis and Gundy Krumins for graphics production. Thanks are also due to anonymous referees for their valued comments. 
$1971-72$.

Table 1: Unemployment rates ${ }^{1}$ in census years by age and sex

\begin{tabular}{lcccccr}
\hline Group $^{2}$ & 1956 & 1961 & 1966 & 1971 & $1976^{3}$ & 1981 \\
\hline Males & & & & & & \\
Teenage & 1.4 & 1.0 & 1.0 & 3.3 & 4.9 & 11.5 \\
Young adult & 1.2 & 0.9 & 0.9 & 1.6 & 2.7 & 6.3 \\
Younger prime-age & 0.8 & 0.6 & 0.5 & 0.8 & 1.3 & 3.4 \\
Older prime-age & 0.8 & 0.6 & 0.6 & 0.7 & 0.9 & 2.0 \\
Females & & & & & & \\
Teenage & 1.4 & 1.3 & 2.4 & 5.8 & 8.0 & 16.5 \\
Young adult & 1.7 & 1.5 & 2.2 & 3.1 & 3.5 & 6.8 \\
Younger prime-age & 1.4 & 1.1 & 1.3 & 1.3 & 1.9 & 3.8 \\
Older prime-age & 0.9 & 0.6 & 0.6 & 0.4 & 0.9 & 2.1 \\
& & & & & & \\
\hline
\end{tabular}

Source: NZ Department of Statistics (various issues) Census of population and dwellings; NZ Department of Statistics, unpublished statistics from the 1976 population census.

Notes:

1. Persons unemployed and seeking work, as a percentage of the full-time labour force of the group.

2. Teenage $=15-19$ years; Young adult $=20-24$ years; Younger prime-age $=25-34$ years; Older primeage $=35-54$ years.

3. The 1976 and 1981 results are for the "usually resident population" whereas preceding years are for the total population (See Braae, 1983). Unemployment rates for both populations were calculated for 1976 and the differences were found to be negligible.

Increases in unemployment rates for a particular population group may reflect diverse kinds of changes in labour market conditions for the group. Unemployment rates may increase in spite of expansion of per capita employment within the group. This may occur, for example, through the labour force participation rate for the group rising faster than per capita employment available. In such a situation the employed, as a ratio of the population group, may be increasing in spite of an increasing unemployment rate for the group; that is, both employment ratio and unemployment rate may increase concurrently. This has been the situation in New Zealand since 1971 for one group of youth, young adult females (20-24 years), as shown in Table 2. Significantly, the expansion of per capita employment for this group of youth has continued without attenuation during the recession since 1975 . In contrast, teenagers of both sexes have shown only decreases in employment ratios, and concurrently with increases in unemployment rates. So the labour market situation of female teenagers during the recession compares very unfavourably with that of young adult females. Female teenagers have not managed to take up job opportunities as have young adult females. The market conditions of male teenagers are poor but not quite as unfavourable as those of female teenagers (Tables 1 and 2). Moreover, employment ratios for males, of all the older age groups examined, have fallen during the recession while their participation rates have been static (Poot and Brosnan, 1982). So as early as 1971 , and during the recession since 1975 , market conditions of female teenagers have been extremely unfavourable in contrast to those of older female youth. The situation of male teenagers has been not quite so poor as their female peers, and the contrast between them and older male youth not so extreme. 
Table 2: Employment ratios ${ }^{1}$ in census years by age and sex

\begin{tabular}{lcccccc}
\hline Group $^{2}$ & 1956 & 1961 & 1966 & 1971 & $1976^{3}$ & 1981 \\
\hline Males & & & & & & \\
Teenage & 67 & 65 & 62 & 55 & 54 & 50 \\
Young adult & 95 & 94 & 93 & 90 & 89 & 85 \\
Younger prime-age & 98 & 98 & 98 & 97 & 97 & 94 \\
Older prime-age & 97 & 97 & 98 & 97 & 97 & 95 \\
Females & & & & & & \\
Teenage & 63 & 63 & 61 & 54 & 47 & 41 \\
Young adult & 50 & 49 & 52 & 53 & 56 & 59 \\
Younger prime-age & 22 & 21 & 24 & 29 & 35 & 40 \\
Older prime-age & 24 & 27 & 31 & 38 & 45 & 49 \\
\hline
\end{tabular}

Source: See Table 1.

Notes:

1. Persons employed for 20 or more hours per week as a percentage of the group.

2, 3. See Table 1 .

\section{Initial Entry}

The inherent characteristics of initial entry into the workforce have been considered a major factor of youth unemployment (Casson, 1979). The individual in school, having reached the statutory minimum leaving age, has 4 alternatives:

(a) continue at school,

(b) leave and take employment,

(c) become unemployed,

(d) leave school but not seek employment.

On the other hand, for the individual already in employment the comparable alternatives are:

(a) continue in present job,

(b) take new job,

(c) become unemployed,

(d) leave the work-force.

A principal difference between the circumstances of the 2 individuals lies in the restrictions on the continuing availability of alternatives (a). A major restraint on (a) for the individual already employed is the risk of dismissal, for example through redundancy. For the individual in school, alternative (a) involves not merely a risk of redundancy but the virtual certainty of it. The school system works on the basis of replacing most entrants to an educational course in little more than the time span specified for the course. In New Zealand, at the statutory school leaving age of 15 years, approximately 85 percent of students will be redundant to the school system within the following 3 years, as not more than 15 percent proceed to full-time education beyond secondary school (Table 4).

For most young people the alternative, (a), of continuing in full-time education can effect only a short-term postponement of one of the other alternatives. It would be expected that the greater restraint on the options of the school leaver than those individuals already in the labour force would have the consequence of greater vulnerability of school leavers to a slackening labour market (Casson, 1979). As a recession sets in, the unemployment rate among school leavers would rise faster than among the remainder of the labour force. Such differential change appears to have occurred in New Zealand during the recession since 1975. Shown in Figure 1a are the Department of Labour unemployment regis- 
Figure 1: Unemployment registration and school leavers

(a) Unemployment registration rates of secondary school leavers and all others (logarithmic scale).
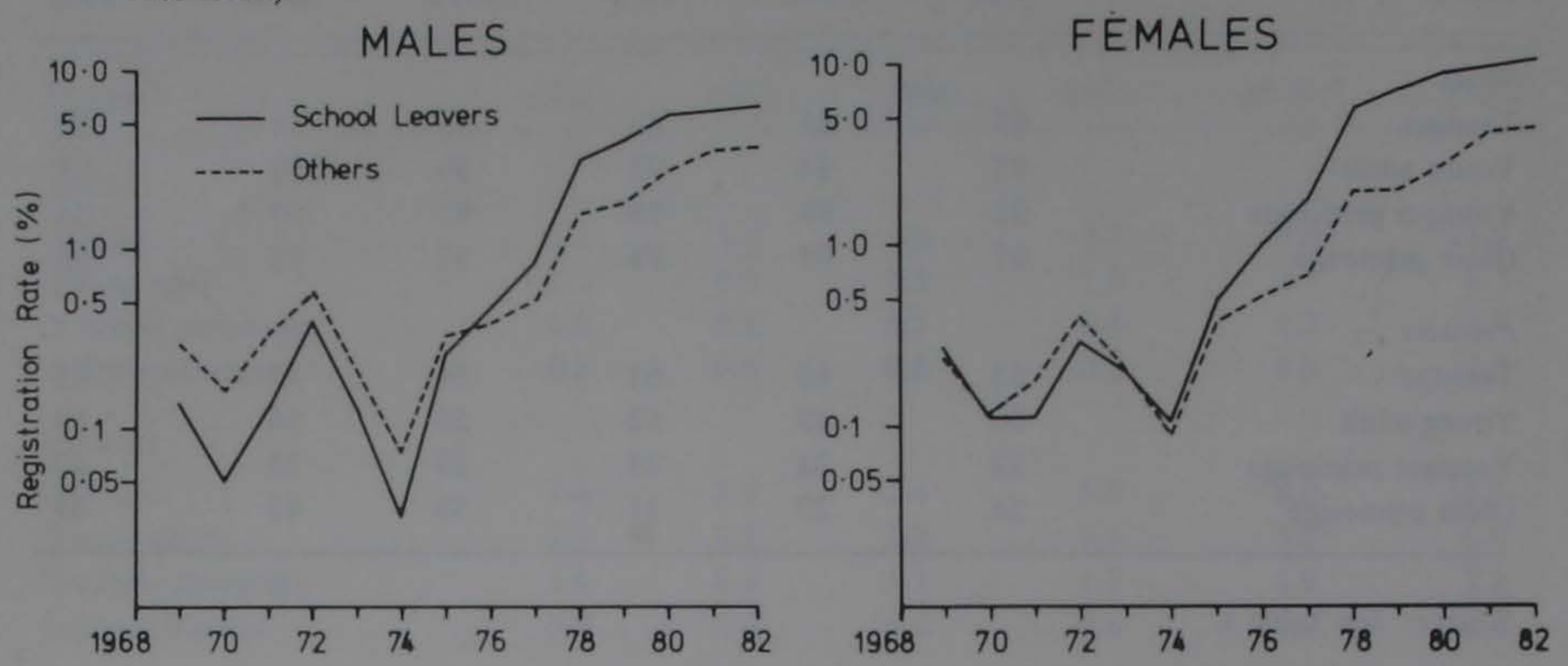

(b) Proportion of school leavers with more than 3 years at secondary school (upper school).
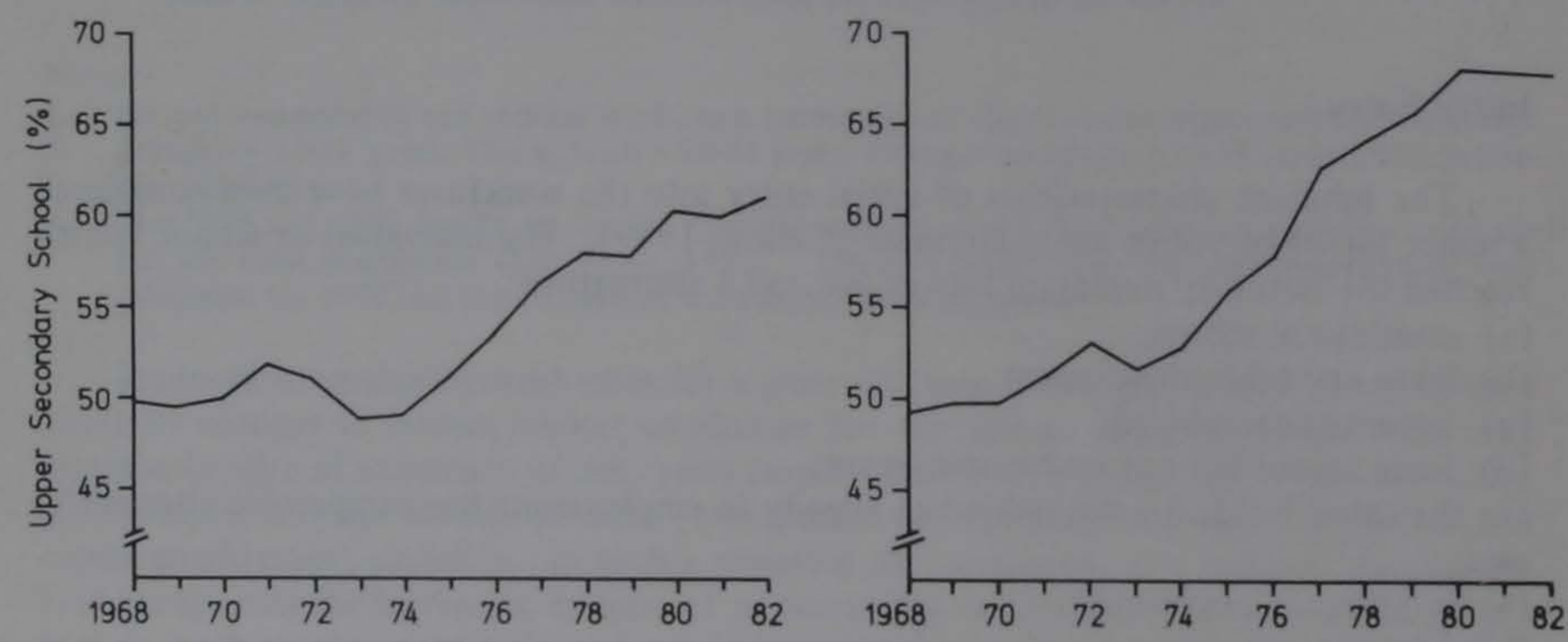

(c) Number of secondary school leavers (graphically smoothed values).
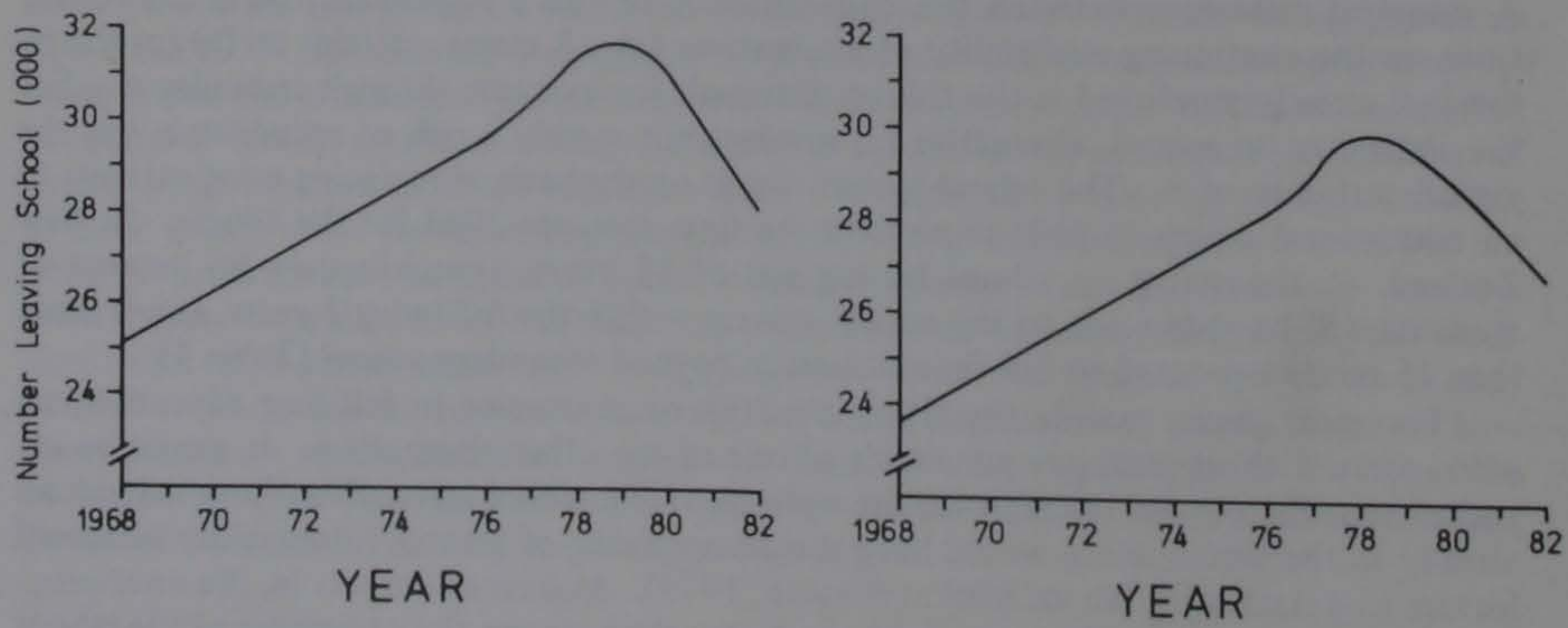

Source: NZ Department of Statistics, Monthly Abstract of Statistics (various issues); NZ Department of Labour, Unpublished monthly statistics of unemployment registrations; NZ Department of Education, Education Statistics of New Zealand (various issues). 
trations of secondary school leavers, expressed as a ratio of the number of persons leaving secondary school, whether for the work-force or further education (Figure 1c). The registration rates are presented on a logarithmic scale, along with the registration rates for all other persons as a ratio of their number in the full-time labour force. (Unfortunately there are no data available by uniform age classifications for the period, nor for classification by first-time entry to the labour force. The present series is available only from 1969). Because of disparate bases, there is not strict comparability between the 2 rates of Figure 1a for any given year, but changes over time may be compared. It is apparent that the registered unemployment rate for school leavers increased substantially faster relative to the rate for all others, as this rate moved above 0.5 percent in $1975-78$, for both males and females.

This differential increase in the 2 rates is likely to reflect some differential increase in unemployment, and not merely a greater increase in the propensity of unemployed school leavers to register with the Department of Labour. Census and registration data analysed by Poot and Brosnan $(1980,1982)$ and updated by the final 1981 census data, indicate that from 1976 to 1981 unemployed teenagers showed a smaller increase in their propensity to register than other unemployed persons. Similar census data on the subgroup of unemployed school leavers are not available but it is unlikely that they would show a trend in their propensity to register so greatly different from other teenagers as to comprise a greater increase than other unemployed persons. The rate of unemployment of school leavers appears to have increased more rapidly than other unemployment from 1975 to 1978 as a major recession set in.

There is, however, a plausible alternative interpretation of these findings. The relatively greater increase for school leavers, as the labour market slackened, may be ascribed to the influence of demographic age changes in which a proportionately larger cohort of young people are attempting to enter the labour force, a situation of "cohort crowding" (Wachter and Kim, 1982; Casson, 1979). A medium-term population change in the distribution of number of young entrants and older individuals of working age might exert an influence on the market position of youth, for example, giving rise to a condition of excess labour supply. Shown in Table 3 are the ratios of the number of 15-19 year olds to the number of 25-54 year olds (prime-age group) in the New Zealand population. The last major medium-term age distribution change of this kind apparently occurred in the 1950s and early 1960s, too long ago to be influencing the labour market during the recession since 1975.

There has been a turn around from annual increases to decreases in number of school leavers since 1979, as may be seen in Figure 1c. By the cohort crowding interpretation it would be expected that such a short-term change in the size of the youth entrant cohort would be reflected in a reduced increase in the rate of school leaver unemployment relative to the rate of other employment. Such a divergence in the rates of registration of the 2 groups of unemployed did not occur during 1979-82 (Figure 1a). Excess supply of young entrants through such demographic changes does not appear to be a satisfactory inter-

Table 3: Population age group ratios

\begin{tabular}{lcccccc}
\hline & 1956 & 1961 & 1966 & 1971 & 1976 & 1981 \\
\hline 15-19 years/25-54 years & & & & & & \\
Males & .19 & .22 & .27 & .27 & .28 & .27 \\
Females & .19 & .21 & .26 & .27 & .27 & .26 \\
$20-24$ years/25-54 years & .16 & .18 & .21 & .24 & .24 & .24 \\
Males & .16 & .18 & .20 & .24 & .24 & .23 \\
Females & & & & & \\
\hline
\end{tabular}

Source: NZ Department of Statistics (various issues) Census of Population and Dwellings. 
pretation of the vulnerability of school leavers in the New Zealand labour market during recent years.

Some investigators have examined the incidence of young people choosing alternative (d), leaving school but not seeking employment (Reubens, Harrisson and Rupp, 1981). The limited evidence of the census data indicates this choice has remained infrequent in New Zealand. The percentages of teenage males who were neither in the full-time labour force nor in full-time education were 1.5, 1.4, 1.5 in 1971, 1976 and 1981 respectively (NZ Department of Statistics, Census). The corresponding percentages for females were 7.6, 7.9 and 7.7, which include those who had commenced work and then withdrawn from the workforce to engage in child rearing. All these percentages include those young people not in full-time education but employed for less than 20 hours per week. The incidence of part-time employment was very low at 0.4 percent for $15-19$ year old males and 1.1 percent for females in 1981.

Notwithstanding the limits on the continuing availability of alternative (a), the postponement of school leaving, it would be expected that additional schooling of short-term duration would be one of the responses young people make to a slackening labour market. A model of this aspect of labour market behaviour has been presented and applied to New Zealand data (Thompson, 1982). In brief, 2 groups were distinguished, the first group of young people continue in secondary school beyond the statutory leaving age because additional schooling and the correspondingly higher qualifications are preferred to fulltime employment at that time; but a second group of young people, in spite of a preference for full-time employment, are in school because they are unable to obtain acceptable employment and (for a time) prefer further schooling to unemployment. The second group are "hidden unemployed" in the schools. The model satisfactorily described the variations in duration of secondary schooling in New Zealand from 1966 to 1981, the short-term variations being responsive to the slackening market conditions in 1967, in 1971 , as well as the conditions of the recession from 1975. The detailed analysis is not repeated here but Figures $1 \mathrm{a}$ and $1 \mathrm{~b}$ enable a visual inspection of the close relationship between short-term changes in registered unemployment and duration of schooling as measured by the percentage of pupils leaving with more than 3 years at secondary school (upper school). Evidence from statistical fitting of the model indicated that secondary schooling can provide a buffer for short-term fluctuations in market conditions for entrants to the full-time labour force, and that in New Zealand such a buffer has been a significant influence on flows of new entrants to the full-time labour force.

The anlaysis also showed that the first group of young people, with a demand for secondary education independent of short-term influences of the labour market, was expanding more rapidly among female than male teenagers. Girls have now substantially overtaken boys in the length of time spent in secondary school (Figure 1b). Nevertheless, for both sexes, over the long term the trend has been towards increased duration of schooling. In New Zealand full participation in primary schooling for all children was achieved by the second decade of this century, and by the seventh decade all children entered secondary school (NZ National Commission for Unesco, 1969; NZ Department of Education, Report of the Minister, 1958-63; NZ Department of Education, Education Statistics, 1964-69). This trend continued during the very slack labour market conditions of the 1930s (McQueen, et al., 1941, p. 20) as well as during the tight conditions of the 1940s and 1950s (NZ Department of Education, Report of the Minister, 1945-60).

Additional schooling for the young person frequently results in additional school qualifications. The exchange value of those qualifications in the labour market may well be a factor in the demand for further schooling and hence changes in the time of initial entry of young people into the full-time labour force. An analysis of changes in the value of school qualifications for young people in the labour market is pertinent to a consideration of the conditions of youth entrants. 


\section{Supply of school qualifications}

An assessment of the value of school qualifications in the labour market requires some description of the conditions governing the supply of these qualifications from the school system. In New Zealand the examination structure is a centralised component of the nation's school system. The examination structure has been changed every few decades by shifting, modifying, or eliminating exams. However, between such points of re-organisation the supply of school qualifications has been governed by the constant pass rate principle: the number passing an exam is prescribed as an approximately constant proportion of the number of individuals attempting the exam. For School Certificate the overall pass rate has been near 0.50 since the exam was introduced in its present form in the mid1940s. It was the pass rate in 1962 when approximately 50 percent of all students attempted the exam before leaving school, and it was the same in 1982 when the proportion attempting the exam was approaching 90 percent. Similarly for University Entrance, the overall pass rate was close to 0.64 in 1962 when approximately 20 percent of students attempted the exam before leaving school. It was still close to 0.64 in 1982 when about 50 percent of students were attempting the exam. (Calculations made from data in NZ Department of Education, Report of the Minister and Education Statistics.)

With a pass rate that is virtually constant, supply of the qualification is directly proportional to the demand for the qualification from young people in the school system. This demand is indexed here as the percentage of all students leaving school who have attempted the exam for the qualification. The constant pass rate is such an entrenched convention of school institutions that there is little awareness of alternatives. Instead of being prescribed as a constant, and hence independent of demand for the exam, the pass rate could be a function of demand, for example decreasing as demand increases, making supply less responsive to demand as demand increases. Another alternative could be an empirical adjustment of pass rates to allow for any shifts in performance level over time, as calibrated through repetition of selected exam questions at intervals of several years.

The constant pass rate principle is useful if the percentage of students attempting the exam varies only within a narrow range. In these circumstances it is a convenient device for facilitating a constant standard where there are inadvertent variations in difficulty levels of examination papers set in different years. However, the constant pass rate principle is problematic when there is a large shift in demand for the exam qualification, and a positive association between marks in the exam, if attempted, and the decision to attempt the exam. For example, with an exam pass rate set at a constant 0.50 , where only 20 percent of students attempt the exam, this 20 percent is more likely to achieve better marks than the other 80 percent if they also were to prepare for the exam. Among this high achieving 20 percent, by the prescribed pass rate, half will fail. Most of that 10 percent would, however, almost certainly be among the students passing the exam if demand for the exam qualification were to shift to a state in which 80 percent were attempting the exam and hence 40 percent passing. So the probability of whether a high achieving student who attempts the exam obtains a pass depends not merely on his or her performance but on the proportion of other students attempting the exam. This peculiarity of the constant pass rate principle holds whenever there is a positive association between the decision to attempt the exam and performance level on the exam; where students who would perform well are more likely to attempt the exam than those who would perform poorly. It seems implausible that there be no such association; that all those not attempting to prepare for the exam would be just as likely to succeed were they to attempt it, as those who do.

Moreover, where the association holds, the constant pass rate yields inherent devaluation of the qualification as the demand for it, and hence supply, increases, unless accompanied by compensating increases in standards of teaching and learning. The question here is whether the rapid increases in the supply of the School Certificate and the University Entrance qualifications which occurred during the past 2 decades (Table 4) have been accompanied by compensating increases in the quality of teaching and learning. Un- 
fortunately there is not adequate objective data available in New Zealand to answer this question (Reid, 1978).

Table 4: Percentage of secondary school leavers with qualifications, and percentage participation in tertiary education

\begin{tabular}{|c|c|c|c|c|c|}
\hline & 1962 & 1967 & 1972 & 1977 & 1982 \\
\hline \multicolumn{6}{|c|}{ School leavers } \\
\hline \multicolumn{6}{|c|}{ School Certificate ${ }^{1}$} \\
\hline Males & 31 & 44 & 46 & 50 & 53 \\
\hline Females & 31 & 44 & 50 & 56 & 58 \\
\hline \multicolumn{6}{|c|}{ University Entrance } \\
\hline Males & 16 & 24 & 26 & 27 & 30 \\
\hline Females & 11 & 18 & 25 & 30 & 33 \\
\hline \multicolumn{6}{|c|}{ Tertiary education } \\
\hline \multicolumn{6}{|c|}{$\begin{array}{l}\text { Full-time participation: } \\
\text { petcentage of } 19 \text {-year-olds } \\
\text { enrolled } 2\end{array}$} \\
\hline Males & 7 & 12 & 15 & 14 & 13 \\
\hline Females & 5 & 8 & 14 & 14 & 14 \\
\hline
\end{tabular}

Source: NZ Department of Education, Report of the Minister of Education (various issues); NZ Department of Education, Education Statistics of New Zealand (various issues).

Notes:

1. For 1972 and subsequently, passes in 3 or more subjects.

2. As at 1 July. Comprises full-time enrolment in university, teachers college, or technical institute.

Both problems of the constant pass rate principle also pertain to multi-grade examinations such as Sixth Form Certificate. In this, results are given in 8 grades but each is assigned a virtually constant percentage of the students attempting the exam. There are constant rates for several grades rather than one for a pass grade.

A constant pass (or grade) rate for a school qualification does not indicate that the inherent value of the qualification, as a level of school achievement, is constant even where there are improvements in teaching and learning in the school system. A greatly increased total supply of school qualifications may not mean a proportionate increase in the inherent value of a stock of qualifications.

\section{Exchange values of school qualifications}

In addition to the inherent value of the qualification as a level of school achievement, there are the exchange values of the qualification. These are of 2 kinds: (1) value in the education system for obtaining a higher qualification, i.e. for upgrading educational qualifications, and (2) value in the labour market, i.e. for obtaining employment. These 2 exchange values of qualifications may vary separately, and independently of the inherent value, whether this be constant or changing.

The exchange value of a qualification for upgrading within the education system is often static over several decades in spite of large increases in supply of the qualification. The School Certificate qualification had the same value for access to schooling for the higher qualification of University Entrance in 1984 as in 1946 when given its present form. The University Entrance qualification is in 1984 the token of exchange for participation 
in tertiary education just as in 1944 when the exam was transferred from the fifth to the sixth form.

The supply of a school qualification available for exchange in the labour market depends not merely on the total supply but also on the proportion of that total exchanged for (successful) upgrading of the qualification within the education system. The remainder of the supply would be that available for exchange in the labour market. For example, calculations from data in Table 4 show that throughout 1962 to 1982 close to 55 percent of males with the School Certificate qualification successfully exchanged School Certificate for the higher qualification of University Entrance. The remainder of males with School Certificate, 45 percent, had that qualification (or Sixth Form Certificate) to exchange in the labour market. For females the proportion was greater prior to 1972. For University Entrance, close to a half of school leavers with the qualification apparently attempted to use it for upgrading to a qualification from full-time tertiary education, the remainder having it available for exchange in the labour market. This latter proportion has been increasing since 1972, as there has been no expansion of participation in full-time tertiary education (Table 4). There has been no such expansion in spite of a continued increase in the supply of the University Entrance qualification which has retained a constant exchange value for participation in tertiary education. Overall, the supply of school qualifications for exchange in the labour market has increased during the period at least as rapidly as the total supply, except in the case of females prior to 1972 when they showed a very rapid increase in the use of School Certificate for qualification upgrading.

The value of the school qualification for exchange in the labour market may not remain static as does the exchange value within the school system. The extent and manner in which the labour market exchange value of a school qualification changes will depend on the functions the qualification has for gaining entry to particular occupations. For some occupations, such as labourers and unskilled operatives, school qualifications are likely to be irrelevant and have no exchange value. For other occupations such as clerical and sales they will be likely to have some exchange value. On the one hand, school qualifications may function to represent a level which is a requisite minimum for coping with the job, while selection among any excess number of applicants with this requisite is made on the basis of other criteria such as age, physical appearance, speech, or personality (Hermann and Davis, 1981). So for entry to these occupations, school qualifications would serve only a partial function in selection of entrants.

On the other hand, school qualifications may serve as a principal means of selecting among any excess number of applicants with the requisite skill level. Unlike the former case, the school qualification then has a "complete selection function" for entry to that occupation. The exchange value of the qualification in the labour market for such an occupation would be expected to decline over time as the supply of the qualification increases among the population of young people. For example, at one point in time with 20 applicants applying for 10 positions, 3 applicants may have qualification A and 6 applicants only the lower qualification $\mathrm{B}$. In this case qualification $\mathrm{B}$, if above the requisite minimum, can usefully serve the complete selection function. However, at some later time the supply of qualifications may increase and, for example, 6 of 20 applicants for 10 positions have qualification A and 12 have only the lower qualification B. Then qualification B would be less useful for the complete selection function. The exchange value of qualification B in the labour market for that occupation would have declined. A general condition is that the qualification be one among a hierarchical ranking of qualifications. Hence, the complete selection function entails a decline in the labour market exchange value of the qualification as the supply of the qualification increases. Such does not occur when the qualification serves only the partial selection function for entry into an occupation.

For jobs where school qualifications have the complete selection function, variation in the slackness of the labour market would be expected to influence the level of qualifications of young people who gain entry to the jobs. For example, for a given level of labour 
market demand, 20 applicants may apply for 10 positions, 3 applicants with qualification $\mathrm{A}$ and 6 with only the lower qualification B; but with a slackening of the labour market, and no change among the population in supply of the qualification, there may be 60 applicants applying for 10 positions, 9 having qualification $\mathrm{A}$ and 18 only the lower qualification. In the first labour market condition few of the 10 selected young people would have the higher qualification A but under the second, slacker market condition, most of the selected young people would. Such shifts in the qualification levels of entrants to jobs would not occur where school qualifications served only the partial selection function intended to ensure of all entrants a requisite minimum skill level for coping with the job. Such a requisite level for the job, where it varies at all, obviously would not vary procyclically with the state of the labour market. If the characteristics of the job changed, necessitating a change in this requisite skill level, such changes would be expected to take a single direction and not vary procyclically with reversals and recoveries of the labour market.

An analysis follows for those jobs, $\mathrm{j}$, where school-leaver entry is gained by school qualifications which serve a complete selection function. Variations in slackness of the labour market, indicated by an aggregate unemployment rate, $U_{t}$, as well as variations in the relative number of positions, $\mathrm{J}_{\mathrm{jt}}$, offered to school leavers in job $\mathrm{j}$, would be expected to influence the level of qualifications of entrants to the job. As changes in the incidence of the qualifications among the school-leaver population would automatically affect the level among applicants and hence entrants, the deviation, $X_{j t}-Q_{t}$, of entrant level of qualifications, $X_{j t}$, from the school-leaver population level, $Q_{t}$, expresses a level of qualifications variable which would be expected to be sensitive to short-term labour market influences. Moreover, in the short-term, $\mathrm{X}_{\mathrm{jt}}-\mathrm{Q}_{\mathrm{t}}$ may be expected to vary negatively with the relative number of job positions offered, $\mathrm{J}_{\mathrm{jt}}$. These relationships may be expressed for a specified job, $\mathrm{j}$, in the following equation of first differences:

$$
\begin{aligned}
\Delta\left(\mathrm{X}_{\mathrm{jt}}-\mathrm{Q}_{\mathrm{t}}\right) & =\mathrm{a}(\Delta \mathrm{t})+\mathrm{b}\left(\Delta \mathrm{J}_{\mathrm{jt}}\right)+\mathrm{c}\left(\Delta \log _{10} \mathrm{Ut}\right) \\
& =\mathrm{a}+\mathrm{b}\left(\Delta \mathrm{J}_{\mathrm{jt}}\right)+\mathrm{c}\left(\Delta \log _{10} \mathrm{U}_{\mathrm{t}}\right)
\end{aligned}
$$

where $\Delta$ symbolises the annual increment of a variable; $t=1,2--n$, represents successive years of the period (and hence $\Delta t=1$ ). It is assumed that the form of the equation applies both to males and females. It is not assumed, however, that the constants $\mathrm{a}, \mathrm{b}$ and $\mathrm{c}$ will always take the same values for males and females, in view of the sex differentiation of occupations; nor is it assumed they will take the same values for different jobs.

The equation has been fitted to a data series which is available on the school qualifications of New Zealand public service clerical cadets $(j=1)$ for the years 1966 to 1981 Similar time series data on other jobs, including those in the private sector, appear not to be available. The level of qualification examined was a qualification higher than School Certificate. Hence $Q_{t}$ was measured by the percentage of school leavers in each school year with a qualification higher than School Certificate (NZ Department of Education, Education Statistics, 1967-82). The percentage increased during 1966 to 1981 from 28 to 41 percent for males and 25 to 46 percent for females. $X_{1 t}$ was measured by the percentage of clerical cadet entrants in March years with a qualification higher than School Certificate (NZ State Services Commission, 1967-82), the percentage increasing during the period from 48 to 74 percent for males and 43 to 61 percent for females. $J_{1 t}$ was the relative number of clerical cadet entrants expressed as a percentage of school leavers of each sex. The values ranged from 1.3 to 2.6 percent for males and 2.0 to 4.5 percent for females. These values serve as a proxy for the relative number of jobs offered.

Data for $U_{t}$ were taken from the series of registered unemployment, as a more adequate series was not available. Nevertheless, for an indication of shifts in the slackness of the labour market, the registered unemployment series has been shown to explain a high proportion of the short-term variation in young people's additional participation in secon- 
dary schooling (Thompson, 1982). As in this earlier study, the unemployment measure in each year was the average of the total registered unemployed of each sex for the months of November and December, rather than averages over the year of monthly data. The state of the labour market in these months near the close of the school year is expected to be critical, being the time at which the majority of school leavers attempt to find employment. The measure of $U_{t}$ was expressed as the number of registered unemployed per 100000 of the labour force. The sizes of the male and female labour forces were taken from Department of Labour estimates. As $U_{t}$ is a measure showing the effect of both an extremely large range and a lower bound, the logarithmic transformation was specified, consistent with the earlier study (Thompson 1982), to give a variable with linear properties.

An ordinary least-squares fit of the equation was determined separately for the male and female data, with the following results for males:

$$
\begin{aligned}
\Delta\left(\mathrm{X}_{\mathrm{lt}}-\mathrm{Q}_{\mathrm{t}}\right)= & -0.23-3.87\left(\Delta \mathrm{J}_{\mathrm{lt}}\right)+7.46\left(\Delta \log _{10} \mathrm{U}_{\mathrm{t}}\right) \quad \overline{\mathrm{R}}^{2}=0.32 \quad \mathrm{DW}=2.32 \\
& (-0.20)(-0.99)
\end{aligned}
$$

and for females:

$$
\begin{aligned}
\Delta\left(\mathrm{X}_{\mathrm{lt}}-\mathrm{Q}_{\mathrm{t}}\right)= & -1.13-2.56\left(\Delta \mathrm{J}_{\mathrm{lt}}\right)+7.41\left(\Delta \log _{10} \mathrm{U}_{\mathrm{t}}\right) \quad \overline{\mathrm{R}}^{2}=0.51 \quad \mathrm{DW}=2.39 \\
& (-1.18)(-1.63)
\end{aligned}
$$

Here $\mathrm{t}=1,2---15$, representing years 1967 to 1981 . The $\mathrm{t}$-statistic for each regression coefficient is given in parenthesis. $\overline{\mathrm{R}}^{2}$ is the coefficient of determination corrected for degrees of freedom. DW is the Durbin-Watson d-statistic, the obtained values of which, in both cases, enable acceptance of the null hypothesis of serial independence of errors. The Glejser test of heteroscedasticity was applied for each of the explanatory variables. In all cases the null hypothesis of homoscedasticity was not rejected ( $p>0.25$ in all cases). An assumption of the above specification is that any time trend of the dependent variable is linear. An alternative specification of a non-linear (quadratic) time trend was estimated by the addition of the $t$ variable to the above equation of first differences. The addition of this variable did not significantly increase the explained variance ( $t$-statistic 0.308 for males and 0.000 for females).

As expected, if school qualifications serve the complete selection function for these clerical entrants, the coefficients for regression on increments of the measure of unemployment, $\log \mathrm{U}_{t}$, were postive and significant ( 0.01 level for each sex, one-tail tests). The coefficients for regression on increments in the relative number of entrants, $J_{1 t}$, were negative as expected, but not significant ( $\mathrm{p}>0.05)$. The a term is the constant component of the annual increments in the deviation of the level of qualifications of job entrants from school leaver population levels. This term was not significantly different from zero for either males or females. Hence, in the medium term, during 1966 to 1981, the deviation from the increasing population level of qualifications has not changed significantly, although there has been short-term variation as a function of labour market slackness.

The level of qualifications of school-leaver entrants to these clerical jobs shows the influence of short-term fluctuations in the state of the labour market, consistent with the supposition that secondary school qualifications serve a "complete selection function" for entry to the jobs. The data are not consistent with school qualifications serving a "partial selection function" for entry. Unlike the partial selection function, the complete selection function entails a decline in the labour market exchange value of the qualification for the jobs, as the incidence of the qualification increases in the school-leaver population. This constrasts with the exchange values of the qualifications in the education system which have been static for upgrading qualifications, and remained so over the period, in spite of marked increases in supply of the qualifications. 
If an appreciable proportion of other white-collar jobs in the market involve this type of entrant selection, then there is a differential between the labour market and school system exchange values of the same secondary school qualification. In the labour market this is declining, and especially rapidly when there is a downturn of economic activity, while in the school system the value is retained for upgrading of the qualification. Not only would the use of the secondary school qualification as a complete selection "gate keeper" for these jobs provide an incentive for young people in the school system, who aspire to such jobs, to upgrade qualifications, but so too would the widening differential between the exchange values of the qualification in the education system and in the labour market.

\section{Conclusions and discussion}

This study examined the position of youth, and especially initial entrants, in the New Zealand labour market over the past two decades. As early as 1971, and during the recession since 1975, market conditions of female teenagers have been extremely unfavourable in comparison with older female youth (20-24 years). The conditions of male teenagers have been not quite so poor as their female peers and the contrast between male teenagers and older male youth is not so extreme. Unemployment among school leavers apparently rose more rapidly than among other persons of the work-force during 1975 to 1978, as the recession set in. The evidence does not support the view that this differential change for school leavers was the result of any increase in the supply of young people relative to other age groups of the working population. The relatively greater increase in unemployment of school leavers is more likely to result from their impending redundancy as students, which is inherent in the school system, and places greater temporal limitations on the alternatives available than is the case for those persons already in employment.

Links between education and the labour market were considered. The constant pass rate principle for the supply of qualifications has been a major factor in the marked increase in the level of secondary school qualifications available for exchange in the labour market. There has been a rapid increase in the proportion of young people holding the University Entrance qualification. In spite of this increase and the constant exchange value this qualification has retained for participation in tertiary education, there has been no increase in the last decade in the rate of participation in full-time tertiary education. In New Zealand there is an absence of flexibility for the addition of full-time tertiary education, compared with the addition of further secondary schooling. In New Zealand, fulltime tertiary education is almost exclusively packaged in units of a minimum of 3 years duration. This involves a different scale of costs to students (or their families) than the single additional year which is available in the secondary school system, and is likely to be a contributing factor limiting participation in full-time tertiary education. It may be noted also that the rate of full-time education participation among the $20-24$ year age group in New Zealand is near the lowest level of the range among OECD countries (Reubens, Harrisson and Rupp, 1981, p. 93). At present, although an increasing proportion of teenagers are qualified for full-time tertiary education, they do not participate and hence enter the labour market where it is likely they displace others not so well qualified, who in turn displace those on lower rungs of the "employment ladder" who are then denied employment (Reder, 1964). In this country youth employment policy has concentrated on "recirculating" those on the lower rungs rather than on their movement up the rungs by increasing the education participation of those higher up.

Notwithstanding the increased per capita supply of secondary school qualifications, their exchange value for qualification upgrading within the education sytem has remained constant. Such constancy was not the case for exchange of the same qualifications throughout the labour market. This was shown in a statistical analysis of a data series on school-leaver entrants to some clerical jobs. As the labour market slackened the qualifica- 
tion level for entry to these jobs tended to increase, and decrease as the market tightened. In addition to these short-term changes in exchange value of entry qualifications, there were longer term changes. As an increasing proportion of the population of young people gained the qualifications there was a corresponding decrease in the exchange values of the qualifications for entry into these clerical jobs. The selection function of qualifications for job entry, which entails such changes in exchange values, was examined and compared with other selection functions of qualifications for entry to other classes of jobs. The changes in exchange value of secondary school qualifications in the labour market contrast with the static exchange values within the school system for qualification upgrading. There is a widening differential between the declining exchange values of qualifications in the labour market for these white-collar jobs and the constant exchange values within the school system.

\section{References}

Braae, R (1983) Establishing comparability between the 1976 and 1981 census labour force definitions. In Easton, B (Ed.) Studies in the labour market Wellington, New Zealand Institute of Economic Research.

Casson, M (1979) Youth unemployment London, MacMillan.

Hermann, GD and Davis DJ (1981) Employment criteria Journal of industrial relations 23: 344-361.

Hicks, J and Brosnan, P (1982) How does New Zealand compare? Some international comparisons of disaggregated unemployment data New Zealand journal of industrial relations 7 (2): 107-122.

McQueen, HC et al. (1941) The background of guidance Wellington, New Zealand Council for Educational Research.

New Zealand Department of Statistics (various issues) Education statistics of New Zealand Wellington

New Zealand Department of Education (various issues) Report of the Minister of Education. Appendix to the journals of the House of Representatives of New Zealand Wellington.

New Zealand Department of Education (various issues) Census of population and dwellings Wellington.

New Zealand Department of Statistics (various issues) Monthly abstract of statistics Wellington.

New Zealand National Commission for Unesco (1969) Compulsory education in New Zealand Revised edition. Paris, Unesco.

New Zealand State Services Commission (1967-82) Report of the State Services Commission. Appendix to the journals of the House of Representatives of New Zealand. Wellington.

Poot, J and Brosnan, P (1980) The propensity to register as unemployed New Zealand economic papers 14 : 93-107.

Poot, J and Brosnan, P (1982) Unemployment and labour force participation : the 1981 census New Zealand population review 8 : 24-34.

Reder, MW (1964) Wage structure and structural unemployment Review of Economic Studies $31: 309-322$.

Reid, N (1978) Standards, basic and national assessment Set : research information for teachers (NZ Council for Educational Research) 1978 (1) Item 13. 
Reubens, BG, Harrisson, JAC and Rupp, K (1981) The youth labor force 1945-1995: a cross-national analysis Totowa, NJ Allanheld, Osmun.

Thompson, GB (1982) The influence of labour market fluctuations on school participation Journal of industrial relations 24 : 535-543.

Wachter, ML and Kim, C (1982) Time series changes in youth joblessness, In Freeman, RB and Wise, DA (Eds) The youth labor market problem: its nature, causes and consequences Chicago, University of Chicago Press. 